Língua e Literatura, n. 20, p. 35-48, 1992/1993.

\title{
O DISCURSO SENEQUIANO E A CARACTERIZAÇÃO DA PERSONAGEM TRAGICA
}

\author{
Zelia de Almeida Cardoso*
}

\begin{abstract}
RESUMO: A linguagem das tragédias de Sêneca revela a grande versatilidade do autor no manejo dos recursos retóricos. Produto de uma época em que se valorizava sobremodo o emprego de elementos ormamentais na composição do texto poético, familiarizado com a preceituação corrente nas "escolas de retores", erudito e sensivel, Sêneca escreveu peças trágicas destinadas principalmente à leitura e se esmerou na construção do discurso literário. Por meio dele e valendo-se da tessitura sonora do texto, dos ritmos poéticos, do conteúdo semântico dos vocábulos empregados, da estrutura sintática dos períodos e dos artificios estilísticos, compôs as personagens e lhes acentuou as características. Hécuba, figura central de As troianas, é um típico exemplo de construção dramática em que os traços definidores da personalidade são conhecidos não só por meio do que ela diz mas sobretudo pelo como diz.
\end{abstract}

Embora já um tanto distanciadas no tempo - Das literarische Kuntswerk é do início dos anos 30 -, as idéias de Ingarden referentes à natureza ontológica da obra poética não perderam a atualidade e podem ainda operar como sustentação teórica para a análise literária. Partindo do método fenomenológico de Husserl, Ingarden (Ingarden, 1973, p. 28-29) chamou a atenção para a estrutura do texto poético e para a sua especificidade, considerando-o como uma tessitura de estratos heterogêneos e distintos, mas interdependentes: o estrato das sonoridades verbais e das formações sonoras, o das unidades de significação, o dos aspectos esquematizados e objectualidades representadas, o das qualidades metafísicas.

Em outras palavras, o texto literário veicula uma "realidade", de determinado ponto de vista e em determinado "tom", e se vale, para isso, do discurso literário, ou seja, de frases tratadas esteticamente, compostas de palavras que se organizam segundo protótipos esquemáticos morfossintáticos; essas palavras, em sua condição de signos verbais, representam a integração de significantes e significados: têm um conteúdo semântico, que pode matizar-se, e a constituição fônica específica da língua a que pertencem.

Assim compreendida, a obra literária é um tecido complexo em que todos os componentes devem ser levados em consideração. Todos agem em conjunto interagem, na verdade - para formar o todo indissociável que é a obra. Na análise,

(*) Professora da Universidade de São Paulo. 
porém, cada elemento pode ser estudado por sua vez, contribuindo o estudo de cada um para o entendimento e a apreciação global do todo.

Para ser completa, a análise deve cobrir o exame de todos os estratos: o da camada sonora, aí contadas as peculiaridades fonéticas e outros elementos relacionados com o som, tais como recorrências fônicas e ritmo; o das unidades significativas denotativas e figuradas; o da estrutura frásica; e, finalmente, o da "realidade" apresentada, quando então se examinará, se for o caso, a intriga diegética, focalizada sob determinada óptica, a conformação das personagens, a caracterização topográfica e cronológica, a mensagem emitida - e, conseqüentemente, as idéias expressas ou sugeridas - e as particularidades próprias do gênero.

Julgando tal esquema bastante adequado à abordagem analítica das obras clássicas - compostas, conforme se sabe, com o rigor de uma verdadeira "construção", com a preocupação de que cada elemento, por mais insignificante que possa parecer, tenha uma função, própria, individual e insubstituível -, procurei ancorarme nos princípios fenomenológicos em estudo que elaborei sobre a composição de As troianas de Sêneca (Cardoso, 1976). De tal estudo faço um pequeno recorte neste artigo e me detenho na análise de Hécuba, personagem central do texto trágico, valendo-me do exame de seu discurso.

Se concebêssemos a peça teatral como espetáculo, outros elementos teriam de ser também considerados. Existe uma simbologia eloqüente por trás de cada fator cenográfico, donde a importância de uma análise semiótica conjunta. Se a compreendermos, porém, como texto - e é esse o caso das tragédias de Sêneca, escritas mais para a leitura que para a representação -, a peça teatral se reduz ao diálogo, ao discurso dramático, devendo este, então, ser analisado em seus estratos constitutivos.

O discurso dramático é mais que uma simples conversação - já o disse Styan (Styan, 1960, p. 11-14) ao procurar caracterizá-lo. Uma frase extraída de uma conversa pode significar pouco; utilizada por um ator, no palco, assume qualidades especiais. $O$ contexto the empresta um valor acima do normal. O próprio ritmo da frase pode sugerir o tom. Mesmo constituído de palavras usuais e baseado na conversação diária, o discurso dramático se submete a uma pressão particular. As palavras têm a função de chamar a atenção. Existe um "subtexto" além do texto.

No caso da tragédia senequiana, considerada por vezes como um modelo de tragoedia rhetorica, o discurso assume dimensões específicas. Os elementos formais são cuidados com extremo requinte. Sêneca é produto de uma época em que se valorizava de modo singular o emprego de elementos ornamentais na composição do texto poético. Familiarizado com a preceituação corrente nas "escolas de retores", erudito, sensivel e versátil, ele trabalhou o discurso literário à exaustão, valendo-se de todos os recursos retóricos possiveis. Compôs, portanto, obras dramáticas nas quais o discurso puro, sem rubricas e didascálias, veicula as idéias, constrói a ação e lhe define a marcha, fornece material para a "visualização" do espetáculo e compõe as personagens. 
Vejamos, como exemplo, o caso da composição da figura de Hécuba, personagem central de As troianas, cujas características podem ser detectadas a partir do estudo de seu discurso.

Sêneca, ao escrever a tragédia, utilizou uma conhecida lenda, explorando o "dia seguinte" da guerra de Tróia. Ao iniciar-se a peça, Hécuba, a rainha vencida, recita o prólogo, falando da destruição da cidade e da sina das mulheres sobreviventes que seriam sorteadas entre os chefes gregos como parte do espólio. Concluindo a exposição, ela assume o papel de corifeu e conduz o párodo - o primeiro canto coral -, dialogando com as troianas e incitando-as a lamentar os mortos ilustres. Nesses dois primeiros momentos o discurso de Hécuba é bastante extenso e se reveste de grande importância.

Terminadas as lamentações, iniciam-se os episódios propriamente ditos. Hécuba não se faz presente nem no primeiro episódio, quando um arauto comunica às mulheres que o espírito de Aquiles surgira das sombras, exigindo a imolação da virgem Políxena fato que ocasiona uma discussão entre Agamêmnon e Pirro, a convocação do porta-voz de Apolo e a confirmação da exigência, acrescida pela do sacrifício do pequeno Astíanax - nem no segundo, quando Andrômaca, a viúva de Heitor, fala de seus pressentimentos e tenta, inutilmente, esconder o filho. No terceiro episódio, quando Helena procura enganar Políxena, simulando que viera prepará-la para um casamento, e no epílogo, quando um mensageiro relata às troianas o duplo crime e as convida a partir, Hécuba está em cena. Suas falas, nesses trechos, embora enfáticas e carregadas de significados especiais, não são muito numerosas.

A função da rainha, portanto, não se configura como preponderante no desenrolar da ação. Sem características evidentes de protagonista, ela se apresenta, no entanto, como uma espécie de eixo que garante a unidade da peça, fazendo a ponte entre o segundo e o terceiro episódio, em sua condição de avó e mãe das vítimas. Conquanto seja um exemplo de "personagem passiva", se constitui, conforme a opinião de L. Herrmann (Sénèque, 1971, p. 57), na "pessoa central" da tragédia, a que encarna e sintetiza a desgraça e o desespero que acomete as troianas. Além do mais, é um elemento de equilíbrio por ter uma função simétrica, recitando o prólogo, responsabilizando-se por algumas das últimas falas do epílogo e permanecendo subjacente nos três episódios centrais.

As características de Hécuba, como antes afirmei, são fomecidas pelo seu discurso. Disse A. Rosenfeld (Souza, 1972, p. 29) que, no teatro, as personagens absorvem as palavras do texto e "passam a constituí-las, tornando-se fontes delas, exatamente como ocorre na realidade" Essas palavras são um dos meios principais para a caracterização. Segundo D. A. Prado (Souza, 1972, p. 88), há três vias que nos levam ao conhecimento de uma figura teatral: o que a personagem revela sobre si mesma, o que faz e o que os outros dizem delas. No caso da tragédia de Sêneca - pobre em movimentação e em eventos e não preocupada com a revelação explícita de dados de personalidade, mas elaboradíssima sob o aspecto retórico e 
formal -, os elementos de linguagem são os grandes responsáveis pela configuração dos tipos.

Conhecemos Hécuba não tanto pelo que diz mas pela forma como o diz; não tanto pelo que faz, mas pelo que incita a fazer por meio da palavra; não pelo que os outros dela dizem mas pelo que diz seu próprio discurso em todos os seus componentes: na organização das frases, nas formas verbais utilizadas, no vocabulário, nas figuras de estilo, no ritmo dos versos, nos fonemas empregados com predileção.

Hécuba é, antes de mais nada, a rainha e, por extensão, a imponência, a majestade, o orgulho. Todas as palavras que pronuncia contribuem para revelar esse caráter. Hécuba é o centro como Tróia o fora, é o chefe, a cabeça, a razão. As primeiras frases que ela alinha, ao abrir o prólogo, colocando-se a si própria no corpo do discurso, nos mostram sua posição em face dos acontecimentos:

\section{Quicumque regno fidit et magna potens dominatur aula nec leues metuit deos animumque rebus credulum laetis dedit me uideat et te Troia.}

\section{(Tro 1-4)}

("Quem confia em seu poder e reina poderoso num grande palácio, quem não teve receio dos deuses inconstantes e se entregou de espírito crédulo a coisas alegres, que me veja agora a mim e a ti, Tróia").

O período, como se pode verificar, é de natureza optativa. O subjuntivo uideat (veja), contido na proposição principal, fazendo-a opor-se ao real das orações subordinadas, que apresentam verbos no indicativo, nas quais se justapõem os presentes fidit (confia) e dominatur (reina) aos perfeitos metuit (teve receio) e dedit (entregou), revela, de forma expressiva, um ato de volição de um agente oculto, disfarçado no paciente objectual $m e$ (me).

O duplo objeto, me (a mim) e te (a ti), mostra-nos a colocação paralela de Hécuba e Tróia. Que se voltem para elas os olhares dos poderosos. Os elementos que caracterizam os eventuais ou potenciais contempladores convocados apresentam cargas semânticas equivalentes ou recorrentes: poder, ausência de medo, alegria. São características opostas às da realidade a ser contemplada.

Hécuba e Tróia, representadas pelos pronomes $m e$ (a mim) e te (a ti), estão no mesmo plano, mas Hécuba vem à frente, mencionada em primeiro lugar e em posição de especial destaque, no início do verso. Tróia vem depois e é focalizada, a seguir, de modo minucioso, em sua ruína e desolação, no amplo quadro descrito pela rainha - um quadro de tristeza, pavor e escravidão, oposto, portanto, semanticamente, ao que anteriormente fora evocado: o poder, o destemor e a alegria. 
As palavras de Hécuba, em sua descrição sinistra, contida entre os versos 6 e 13, convergem para a frase-chave presente no verso 14: Pergamum incubuit sibi ("Pérgamo caiu sobre si mesmo"). É o desmoronamento total, o fim.

A derrocada de Tróia se deveu a dois fatores: a sanha do inimigo e as armas de guerra. Do verso 15 ao 66, há uma série de recorrências significativas que envolvem tais idéias. Palavras como adustis (queimados), flammae (chamas), ardens (ardente), fumat (fumega), fumo (fumaça), fauilla (fuligem), cineres (cinzas), ignes (fogos), facibus (fachos), ardetis (ardeis) caracterizam o fogo, usado como arma; armis (armas), ferrum (ferro), ensis (espada) denotam as armas propriamente ditas. De outro lado, expressões como auidas manus (mãos insaciáveis) avidus irae (enfurecido), rapit (saqueia), ferus (cruel), populator (devastador), ferox (feroz), qualificam o inimigo. É a queda do baluarte destruído, o ferro, o fogo, a vitória do exército oponente.

Tróia e Hécuba foram derrotadas e destruídas, conforme se pode depreender. As últimas palavras da rainha, entretanto, já no final do epílogo, nos mostram sua posição, diferente, agora, da de Tróia:

Non hostis aut ruina, non ignis meos absumpsit artus /.../

(Tro 1176-1177)

("Nem o inimigo, nem o desmoronamento, nem o fogo atingiu meus membros ...")

Hécuba, fisicamente viva e incólume, se opõe a Tróia arrasada. Mas na vida de Hécuba é que se encontra realmente sua morte. E aí compreendemos a suposta contradição da velha rainha no párodo quando, após ter ordenado às troianas que chorassem o rei morto, as intima a parar com as lamentações:

Felix Priamus!

dicite cunctae: liber manes

uadit ad imos, nec feret umquam

uicta Graium ceruice iugum.

(Tro 143-145)

("Feliz Príamo!

dizei juntas. Livre, ele se dirige

às profundezas dos manes e jamais trará

o jugo helênico sobre a vencida cerviz').

A morte do rei livre se identifica com a felicidade. A desgraça, pior que a morte, é a escravidão, a escravidão que anulará a majestade da Hécuba-rainha, 
acostumada a dirigir-se à turba das troianas no imperativo, o modo do mando: ferite pectora (feri vossos seios), planctus date (erguei vossa lamentação), iusta Troiae facite (fazei coisas dignas de Tróia), soluite crinem (soltai as cabeleiras), solitum flendi uincite morem (superai vosso costumeiro hábito de chorar), saeuite (enfurecei-vos), tundite pectus (golpeai vosso peito), uertite planctus (vertei vossas lágrimas), fundite fletus (derramai vosso pranto), dicite cunctae (falai conjuntamente) (Tro 64-144).

A escravidão fere de frente o orgulho de Hécuba, que sente vergonha de seu dono:

$\begin{array}{lc}\begin{array}{ll}\text {... } \\ \text { non seruitutis. }\end{array} & \text { domini pudet } \\ & (\text { Tro 989-990) } \\ \text { não da servidão"). } & \text { ("tenho pejo de meu senhor, }\end{array}$

Hécuba se envergonha de ter Ulisses por amo. Como se envergonharia de ter Pirro, Menelau ou Agamêmnon. A vergonha surge no momento em que sabe que tem um senhor, pois que nenhum a mereceria. A escravidão como abstração seria ainda tolerável: é uma vicissitude, uma decorrência natural da guerra; a escravidão concretizada - qualquer que seja o dono - essa é intolerável porque afronta o orgulho. A escravidão se opõe à arrogância de Hécuba que exorta as companheiras a desnudar os seios em uma atitude de revolta (Tro 89-90), que se dirige a Ulisses com ameaças (994-996) e a Pirro com desafios (1000-1002). Em qualquer dos casos é Hécuba-rainha quem fala. É Hécuba-Tróia que cai sobre si mesma mas que se transforma numa nuvem de fumaça, retomando a posição vertical, pairando acima de todos e levantando a cabeça sem sentir o peso do jugo sobre a cerviz.

O discurso da rainha é pessoal e emotivo. Sua literalidade se superpõe, por vezes, a seu aspecto referencial. As palavras que diz são importantes em si, insubstituíveis. A própria tradução prejudica o aspecto conotativo e expressivo do texto. Como traduzir, por exemplo, as admiráveis séries de consoantes dentais encontradas nos versos 3-4 e 93-95, a sugerir um gaguejamento soluçante e patético?

$$
\begin{aligned}
& \text {... laetis dedit } \\
& \text { me uideat et te, Troia... }
\end{aligned}
$$

... placet hic habitus,

placet: agnosco Troada turbam.

Iterum luctus redeant ueteres...

(Tro 93-95) 
Qualquer tentativa de tradução falsearia o original, tiraria sua força expressiva, diminuiria o impacto que causa no receptor.

O discurso é extremamente rico e, por conseguinte, complexo e de dificil análise. Apresenta a todo momento figuras estilísticas de importância funcional, entre as quais predominam as de pensamento, importantes para a configuração da personalidade da rainha.

Destacam-se as alusões, as interrogações, as exortaçōes, as imprecaçōes, as acumulações, as antíteses.

As alusões - referências vagas a fatos, lugares, pessoas e coisas pressupostamente conhecidos - evocam, principalmente, a guerra, a família e os mitos. A pátria destruída, a ancestralidade real e a participação dos deuses na vida são os responsáveis diretos pelas lembranças constantes do passado. $O$ passado evocado é trazido ao presente e se transforma, realmente, no presente de Hécuba. Passa ela, então, a viver o passado no presente. Só o passado parece existir e superpor-se a uma atualidade que ela não quer viver. Embora cruel, o passado é revivido nas alusões e a crueldade que encerra é menor, talvez, que a crueldade do presente, que não oferece nada. O passado, ao menos, pode oferecer as recordações que sustentam a rainha.

No início do prólogo, Hécuba faz alusões principalmente à guerra. Tudo é lembrado em evocações pouco precisas que pressupõem conhecimento por parte do leitor/espectador da tragédia. Não há um relato do que aconteceu. As lembranças existem mas não são apresentadas; são insinuadas. Com poucas palavras Hécuba reconstrói um quadro, faz-nos visualizar uma cena. Em vinte e um versos - do 6 ao 27 -, ela relembra a totalidade da guerra. E podemos ver as muralhas derrubadas no chão, muito embora tivessem sido construídas por Apolo e Netuno (caelitum egregius labor - Tro 7), muito embora toda a Ásia conhecida se tivesse aliado a Tróia para impedir tal desenlace: os guerreiros de Reso, os citas, os povos orientais coligados, as amazonas. A guerra não respeitou a casa real: o palácio de Assáraco é uma fogueira imensa a expelir rolos de fumaça para o alto; a escuridão esconde o céu e o vencedor se apodera do espólio.

Evocada a pátria, destruída e saqueada, Hécuba relembra a família, desintegrada e dispersa. Alude a Heitor, aos filhos mais jovens também mortos, a Cassandra, a Páris. Alude a Príamo, morto por Pirro e condenado a permanecer sem sepulcro (Tro 28-55).

Essas alusões nos mostram uma Hécuba vinculada ao passado, impossibilitada de libertar-se dos antigos laços. E o fato é perfeitamente compreensivel: no passado Hécuba viveu e reinou, teve o amor de Príamo e o carinho dos filhos, foi poderosa e grande. A vida, o amor, a majestade só existem agora como lembranças mas são a única coisa concreta que a rainha ainda possui. O presente e o futuro só lhe oferecem o caos.

A passagem brusca do poder ao nada, da realeza à escravidão, do pináculo ao solo, explicam as outras ocorrências do discurso de Hécuba. 

ca. Língua e Literatura, n. 20, p. 35-48, 1992/1993.

As interrogações - presentes em grande número em suas falas - estão geralmente soltas no meio do discurso. Mas não são indagações feitas a alguém com o objetivo da obtenção de uma resposta; são meras perguntas propostas ao acaso, revelando a perplexidade da rainha diante do inexplicável e talvez o desejo inconsciente de encontrar uma explicação.

Sed quid ruinas urbis euersae gemis, uiuax senectus?

(Tro 41-42)

("Mas por que gemes a ruína de uma cidade caída, ó minha velhice que resiste à morte?"),

pergunta Hécuba no correr do prólogo. A pergunta é proposta a si própria e tem caráter meramente retórico.

Mais adiante, ao-dialogar com as troianas, a interrogação da rainha tem caráter exclamativo e tom exortativo. Após incitar as mulheres a desnudar-se em sinal de luto e protesto, a rainha indaga:

$$
\begin{gathered}
\text { Cui coniugio } \\
\text { pectora uelas, captiue pudor? } \\
\text { (Tro 89-90) } \\
\text { ("Para que casamento }
\end{gathered}
$$

Não é a resposta, o conhecimento da causa, o que interessa; é a mudança de atitude das mulheres que a ouvem, fato que deverá decorrer da indagação proposta, como uma conseqüência natural.

Em outro passo, ao dirigir-se a Pirro, no momento em que o jovem aprisionava Políxena e rechaçava a oferta da rainha, disposta a acompanhar a filha, a pergunta formulada tem todas as características de um desafio, de uma invectiva; apenas a forma é de interrogação:

Pyrrhe, quid cessas?

(Tro 1000)

("Por que paraste, Pirro?")

Em geral, a indagação de Hécuba pressupõe uma resposta implícita. E numa ocorrência, no final do terceiro episódio, quando ela se vê totalmente impotente para mudar a marcha dos acontecimentos, a resposta chega a ser dada explicitamente nas palavras que endereça aos inimigos: 
Quid precer uobis? Precor
his digna sacris aequora; hoc classi accidat
toti Pelasgae, ratibus hoc mille accidat
meae precabor, cum uehar, quicquid rati.

(Tro 1005-1008)

(“Que pedirei para vós? Peço

mares dignos deste sacrificio. Que aconteça à armada pelásgica, que aconteça aos mil navios aquilo que eu pedir para o meu navio quando eu for levada").

Admiráveis pelo efeito estilístico e pelo patético que encerram são duas séries de interrogações encadeadas que configuram também, simultaneamente, dois casos de gradação.

A primeira é marcada pelo emprego enfático de anáfora e paralelismo:

Quis tam impotens ac durus et iniquae ferus sortitor urnae regibus reges dedit?

Quis tam sinister diuidit captas deus?

Quis arbiter crudelis et miseris grauis

eligere dominos nescit et saeua manu

dat iniqua miseris fata? Quis matrem Hectoris

armis Achillis miscet?

(Tro 981-987)

("Qual foi o furioso, mesquinho e feroz sorteador de uma urna iniqua que deu rainhas aos reis?

Qual é o deus tão sinistro que separa as escravas? Qual é o árbitro, cruel e opressor para as infelizes, que não sabe escolher senhores e, com mão impiedosa, traça um destino vergonhoso para as desgraçadas?

Qual é aquele que misturará a mãe de Heitor às armas de Aquiles?")

Construiu-se um crescendo cujo ponto alto é a frase final. Os tempos verbais empregados contribuem para a composição da gradação. $O$ perfeito dedit (deu) é substituído pelos presentes diuidit (separa), nescit (não sabe) e dat (traça) e, finalmente, pelo futuro miscet (misturará). A última interrogação se reporta a um fato que ainda não ocorreu. Embora Hécuba já pertença a Ulisses pelo sorteio e ela o sabe - a posse real ainda não se concretizou. É uma possibilidade futura, portanto, e não um fato consumado. 
A segunda série de interrogações encadeadas, presente no final do epílogo quando tudo se acabara, inclusive as esperanças -, se caracteriza pelo excessivo cuidado com o aspecto fônico:

Quo meas lacrimas feram?

Ubi hanc anilis expuam leti moram?

Natam an nepotem, coniugem an patriam fleam?

An omnia an me?

(Tro 1168-1171)

("Para onde levarei minhas lágrimas?

Onde repudiarei a tardança da morte de uma anciã?

Deveria chorar minha filha ou meu neto? Meu esposo

ou minha pátria? Tudo ou a mim própria?")

A camada sonora do texto latino agrava as conotações de desolação, desalento e desânimo que a unidades de sentido apresentam. Das cinqüenta consoantes utilizadas, vinte e três - quase a metade - são consoantes nasais, o que acentua a idéia de cerceamento, de abafamento, de limitação, de fim de um ciclo que se fecha.

Além das alusões e interrogações, são também freqüentes, no discurso de Hécuba, as exortações, que surgem como incentivo ou ordem e que caracterizam, evidentemente, a fala de uma rainha acostumada a comandar. No párodo, os imperativos dirigidos às troianas, $\mathrm{e}$ já mencionados antes, se configuram como imperativos exortativos. Ao dirigir-se a Pirro, entretanto, e aos demais chefes gregos, os imperativos de Hécuba mudam de configuração e assumem as funções de invectivas e imprecações:

reclude ferro pectus et Achillis tui

Age

coniunge soceros. Perge, mactator senum, et hic decet te sanguis: abreptam trahe. Maculate superos caede funesta deos, maculate manes.

(Tro 1000-1005)

Fere meu peito com teu ferro e reúne os sogros

(“Anda! de teu Aquiles. Continua, assassino de velhos, é este o sangue que te convém. Arrasta-me! Maculai, vós todos, os deuses superiores com um crime funesto. Maculai os manes".) 
Menos comuns são as optações, no discurso da rainha, e isso pode ser explicado se atentarmos para a própria natureza da optação, figura pela qual se expressa um desejo. Hécuba já nada mais deseja de consistente, de concreto. Suas optações se confundem com imprecações ou ironias:

\section{Iamdudum sonet}

fatalis Ide, iudicis diri domus;

$$
\text { (Tro 65-66) }
$$

("Que agora ressoe

o Ida fatal, sede de um juramento desastrado!');

maesta capilli tepido Troiae

... per colla fluant

puluere turpes;

(Tro 84-85)

("que flutuem sobre vossos

tristes ombros os cabelos sujos

com a cinza quente de Tróia");

Rhoetea sonent litora planctum habitansque cauis montibus Echo non ut solita est, extrema breuis uerba remittat: totos reddat Troiae gemitus: audiat omnis pontus et aether.

(Tro 107-112)

("Que a praia do Reteu ressoe com o pranto e Eco, habitante das grutas escavadas, não repita apenas as últimas palavras, breve como é: que reproduza todos os gemidos de Tróia: que os ouçam os mares e o ar").

Também não são muito assíduas as exclamações: talvez para Hécuba já nada mais seja motivo de espanto ou admiração. Esporadicamente, porém, encontramse expressões exclamativas, muitas vezes repassadas de ironia. A ironia, aliás, considerada por G. G. Sedgewick (Sedgewick, 1948, p. 703 seqs.) como elemento fundamental na tragédia, onde o próprio revés da fortuna é irônico, perpassa o discurso de Hécuba revelando a revolta da mulher que não se dobra, não se verga, não cede e prefere a morte à humilhação de ser vencida. 

ca. Língua e Literatura, n. 20, p. 35-48, 1992/1993.

Um caso especial de ironia pode ser observado em sua última fala quando, ao dirigir-se aos gregos, Hécuba formula votos para a partida:

Ite, ite, Danai; petite iam tuti domos;

optata uelis maria diffusis secet

secura classis: concidit uirgo ac puer;

bellum peractum est.

(Tro 1165-1168)

("Ide-vos, ide-vos, dânaos; demandai vossos lares com segurança; que a armada confiante corte os mares almejados, velas à solta: tombaram a virgem e o menino;

a guerra terminou").

Ao lado dessas figuras, que, enriquecendo estatisticamente o discurso, são fundamentais para a construção do caráter da personagem, muitas outras poderiam ser levantadas: acumulações, antíteses, figuras de harmonia, sempre empregadas com papel funcional.

As figuras de estilo por vezes se revestem de valor simbólico, operando como índices. Veja-se, por exemplo, o seguinte caso de acumulação, em que existe pleonasmo léxico:

$$
\begin{aligned}
& \text {... nube ceu densa obsitus } \\
& \text { ater fauilla squalet Iliaca dies. }
\end{aligned}
$$

("... como que coberto por densa nuvem, o negro dia se obscurece com a fuligem de Tróia").

Poderíamos considerar tal acumulação como mero recurso enfático ou nela tentar reconhecer o extravasamento de um pensamento obsessivo, a revelação da fixação de uma idéia.

Da mesma forma, as antíteses podem ser consideradas quer como simples adorno de linguagem quer como reflexo natural do pensamento de alguém que é a própria encarnação da antítese, condensando em si a realeza e a escravidão, o ódio e o amor, a altivez e o abatimento.

No início do primeiro pronunciamento de Hécuba já se observa a marca da antítese da qual ela é o exemplo vivo:

... non unquam tulit

documenta fors maiora, quam fragili loco

starent superbi.

(Tro 4-6) 


\section{("... jamais a Sorte}

apresentou provas maiores de como os poderosos se assentam sobre tão frágil base").

Se as figuras de estilo contribuem para o conhecimento da personalidade da rainha, o mesmo se pode dizer das palavras que escolhe, ricas em valor simbólico e conotativo, e dos elementos sonoros que compõem os significantes.

São abundantes, no discurso, como se viu, os vocábulos que evocam fogo, chamas, fumaça, cinza, bem como os que denotam sofrimento, luto, pranto, morte, dor. Por outro lado, aparecem com insistência aliterações decorrentes do emprego de palavras com cadeias de dentais, sugerindo entrecortamento de fala, próprio de quem soluça, ou com elementos nasais que lembram o abafamento e a sufocação. A utilização de sílabas longas, em excesso, também contribui para a criação de um discurso pesado. O párodo, em que dialogam Hécuba e as troianas, é construído com versos anapésticos, o que deveria conferir leveza ao texto, caso os anapestos fossem mantidos, uma vez que tal pé métrico se compõe de duas sillabas breves seguidas de uma longa. Sêneca, porém, substitui muitos dos anapestos por espondeus - formados por duas sílabas longas -, sobretudo quando é Hécuba quem fala. Encontramos em alguns versos espondeus justapostos, o que, no dizer de Quintiliano (Inst Orat IX 4 139), cria o tumor tragoediae, dada a sua solenidade, a grauitas da expressão vocal.

Em dois momentos encontramos três espondeus consecutivos numa série de quatro pés, o que alonga sobremaneira a fala, fazendo-a grave, pesada, apropriada, portanto, ao que expressa:

Fi $\mid$ dae $\mid$ ca $\mid$ sus $\mid$ nos $\mid$ tri $\mid$ co $|\mathrm{mi}|$ tes

(Tro 83)

("Companheiras fiéis de nossa desgraça");

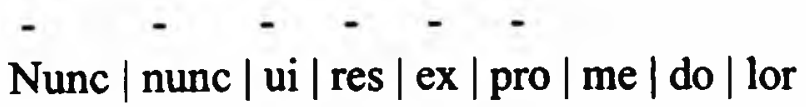

(Tro 106)

(“Agora, agora, ó dor, mostra a tua força!").

Todos esses recursos tornam o discurso de Hécuba extremamente rico, solene, grandioso, diferente do das demais personagens da peça e adequado à envergadura da rainha. $\mathrm{O}$ artificialismo - que fez com que alguns críticos, como Patin (Patin, s/d, p. 411), a considerassem como "um retor que brinca com o sofrimento e disserta com ênfase sobre ele" - tem importância estrutural. O que Hécuba diz 

ca. Língua e Literatura, n. 20, p. 35-48, 1992/1993.

tem sua função, evidentemente, por revelar a verdade que se pretende mostrar e acentuar a tragicidade existente na vida como uma ameaça constante, dependente da fortuna e do acaso. $\mathrm{O}$ como diz, no entanto, é o dado fundamental para a caracterização da personagem. Se considerarmos a rainha como um ser majestoso, soberbo, altivo, acostumado ao mando e ao respeito, capaz de levar os sofrimentos aos extremos, de odiar e amar, de desafiar os poderosos e expor-se ao perigo, mergulhada sempre no sofrimento mais profundo, numa dor sem consolo e sem remédio, sabemos de tudo isso não por unidades significativas diretas mas por um jogo lingüístico e retórico para o qual contribuem em conjunto, de forma decisiva, todos os elementos constitutivos do discurso: as sonoridades - dos fonemas ao ritmo, passando por figuras de harmonia e até de sintaxe -, os signos empregados em suas funções próprias e conotativas, a frase, construída com evidente cuidado. Todos os estratos, conjuntamente, formam a tessitura una e indissociável que nos dá a medida da personagem em sua participação na ação dramática.

\section{BIBLIOGRAFIA}

CARDOSO, Z. A. A construção de As troianas de Sêneca. São Paulo, USP, 1976 (Tese de doutoramento, policopiada).

HERRMANN, L. Ver SÉNEQUE, Tragédies.

INGARDEN, R. A obra literária. Lisboa, Fundação Galouste Gulbekian, 1973.

PATIN, M. Etudes sur les tragiques grecs. Paris, Hachette, s/d.

PRADO, D. A. Ver SOUZA, A. C. M. et alii.

RIFFATERRE, M. Estilistica estrutural. São Paulo, Cultrix, 1973.

ROSENFELD, A. Ver SOUZA, A. C. M. et alii.

SEDGEVICK, G. G. On irony, specially in drama. Toronto, University of Toronto Press, 1948.

SÉNEQUE. Tragédies (Texte ét. \& trad. par L. HERRMANN). Paris, "Les Belles Lettres" 1971.

SOUZA, A. C. M. et alii. A personagem de ficção. São Paulo, Perspectiva, 1972.

STYAN, J. L. The elements of the drama. Cambridge, Cambridge University Press, 1960.

TODOROV, T. Estruturalismo e poética. São Paulo, Cultrix, 1971.

WELLEK, R. e AUSTEN, A. Teoria da literatura. Lisboa, Europa-América, 1962.

\footnotetext{
ABSTRACT: The language used by Seneca in his tragedies reveals a great versatility in dealing with rhetoric resources. Product of an age when excellence was chiefly given to the application of decorative elements in the poetic text composition, acquainted with the prevailing precepts in the "schools of rhetoricians", learned and sensible, Seneca wrote tragic plays specially designed to be read and was deeply concerned about shaping the literary discourse. Through it and making use of the phonic elements of the text, the poetical rhythms, the semantic contents of the words, the syntactic structure of clauses and the figures of style, he built the characters and emphasized their features. Hecuba, the central dramatis persona of Trojan women, is a typical example of dramatic construction whose defining traces of personality are known not only by means of what she says but also by how she says it.
} 